\title{
Clinital alotes:
}

\section{MEDICAL, SURGICAL, OBSTETRICAL, AND THERAPEUTICAL.}

\section{GANGRENOUS ABSCESS OF THE LUNG TREATED BY INCISION AND DRAINAGE; RECOVERY.}

BY Solomon C. Smrth, M.D., SURGEON TO THE HALIFAX INFIRMARY.

IN THE LANCE'T of Jan. 17th, 1880, I recorded a case in which I dained a gangrenous abscess of the lung, giving thereby much relief, but not saving the patient from death, which took place in about a fortnight. I now report a case of the same nature, although with less urgent symptoms, in which a similar line of treatment was successful.

E. $\mathrm{H}-$, a woman aged thirty-nine, was seen by me on March 18th, 1889, in consultation with Dr. Bindley of Brighouse. Her illness had commenced a fortnight before, with feverishness, general malaise, and cough. At the end of a week she got up, but was taken worse the next day with pain in her chest; the cough became more troublesome, and within a day or so the expectoration was observed to be offensive. When I saw her she was very feeble, not very short of breath when lying down, but the effort of sitting up in bed produced both faintness and dyspnoa. The pulse was quick, and its rate easily disturbed; the appetite was not bad, and there was no diarrhœa; but there was a good deal of perspiration, and the temperature had kept up between $101^{\circ}$ and $103^{\circ}$. Her chief complaint was of extreme weakness and of violent attacks of cough, sometimes lasting hours together, and producing only slight and difficult expectoration, which, however, was exceedingly fetid, sickening both her and her attendants. The paroxysms of cough were often separated by intervals of several hours. Below the point of the right scapula there was dulness, not very marked, and not extending quite to the base; and over and around the dull area the respiratory sounds were abolished, except on coughing, when moist sounds were heard, but not very distinctly. During the next month her condition steadily deteriorated, and on April 21st she was found extremely weak, with quick, feeble pulse, frequent perspirations, failing appetite, and constantly recurring cough, with expectoration of a thin yellowish-brown fluid, of a very offensive odour, which made the whole atmosphere of the room sickening to a degree. In the early days of her illness the expectoration had occurred at considerable intervals, but now it came on so often that it entirely prevented her from satisfying such little appetite as she had, every attempt to swallow immediately setting up cough, and filling the mouth with this offensive expectoration. There was now distinct gurgling to be heard occasionally below the right scapula on coughing, with loud cavernous cough sounds. The largest quantity of fluid ejected at one paroxysm was about a teacupful. Operation was advised, but was not consented to until May 12th, when her condition had become apparently desperate; coarse moist sounds were audible over the opposite lung, and she was evidently sinking rapidly. An aspirator inserted for about three inches into the site of the loudest cough sounds drew away nothing; but on making an incision into the same spot, and boring inwards with a " sinus" forceps, the blades of which were then opened, it was obvious, from the free mobility of the point and from the expectoration becoming immediately blood-stained, that a cavity had been entered. The opening was then extended so as easily to admit of the insertion of two drainage-tubes, of as large a calibre as would lie uncollapsed between the ribs. There was very little discharge-I should say less than an ounce; but the fetor was extreme, so much so that the smell clung to my hands for many hours, notwithstanding all my efforts to remove it.

From the date of the operation her recovery has been steady and continuous ; since that afternoon the expectoration has never again been fetid, and in a very few days the discharge through the tube became sweet, and has remained so. It is curious to remark how small in quantity the discharge has been, and how ropidly the expectoration diminished; it seemed as if the free dependent opening at once removed all the difficulty; the appetite returned, the cough and expectoration diminished, the fetor vanished, and when I saw her last, on June 6th, she was up and walking about. The tube, of course, still remains in place. Halifax.

\section{REJUVENESCENCE OF THE HAIR OF THE HEAD AND BEARD.}

By William O'Neill, M.D., M.R.C.P. Lond., \&c.

I WISH to mention very briefly an interesting feature or two in the case of a gentleman who has recently been under my care.

Mr. $\mathbf{T}_{-}$- who was sixty-five years of age and very tall and slender, suffered for many years from chronic rheumatism of a most painful character. Once he had a severe attack of bronchitis, but he never presented any symptom of heart, liver, or kidney disease, and his digestion was fairly good for a man who spent most of his time in in-door occupations. Six years ago, when he was well able to attend to his business, he was suddenly seized, without any previous warning, with palsy of the right side, slight deafness of the right ear, and ocular derangement which caused him to see objects double. His speech was not in the least affected, neither had he any appreciable paralysis of the face or tongue. The mind was somewhat confused at the time of the seizure, but it soon regained its usual strength and vigour. The paralysed limbs, however, never acquired much increase of power, the muscles wasted, and some of the flexors became contracted and rigid. The fingers of the right hand became flexed on the palm and the forearm on the arm. Mobility and sensibility in the limbs were very deficient, but the leg retained more nerve power than the arm. Any movements of the diseased limbs caused a good deal of pain ; consequently it was almost impossible to persuade the patient to exereise them either in an active or passive way. A short time before Mr. T- had his seizure a very tall thin man was also attacked with right hemiplegia. In his case, however, the speech was much affected; and, although he is living and in good health, the aphasia and the paralysis have not greatly improved. In both these men the outward and visible signs of paralysis or disease seemed to be precisely similar, and it is only by a knowledge of the locality of the inward lesion that an explanation can be oiven why it is that in the case of $\mathrm{Mr}$. $\mathrm{T}$ the stream of language flowed strongly and smoothly, and that in the other case the stream is defective, broken, and interrupted. The cause of the palsy in these patients I attribute to enubolism, and the great length and the small calibre of the carotids of the necks had something to do, I think, with the formation of the plugs.

But what I wish more especially to mention in connexion with the case of Mr. T - is that up to about two years and a half ago he was both bald and grey-haired. About that time, however, dark hair began to grow on the bald patch, and the grey hair of the head and the beard began to fall and to be replaced by hair also of a dark-brown colour. These processes of renewal or restoration went on until the hair on the patient's head and chin had assumed the appearance which it had when he was a young man of twenty-five or thirty years of age. His wife and relatives believe that this new growth of hair was caused by chlorodyne, which the patient had acquired the habit of taking in large quantities. Three years ago he was induced by someone to try chlorodyne as a remedy against pain. At first the doses were small and insignificant, but he soon got to take two or three teaspoonful doses or more several times a day. Whether the chlorodyne had anything to do with the new growth of hair, I do not know. But even supposing it is a hair-restorer or rejuvenator when taken in the way that $\mathrm{Mr} . \mathrm{T}$ - took it, still the remedy is worse than the disease, or, according to the old adage, "the game is not worth the candle," for there is no doubt that, when chlorodyne is taken in large doses for a length of time, it will produce the most injurious effect on the constitution. Lincoln.

THE MECHANISM OF THE BILIARY SECRETION. By VAUghin Harley, M.B.

IN an interesting paper entitled a "Lnique Case of Biliary Fistula," at p. 1075 of THE LANCET of June 1st, Mr. Copeman remarks that the secretion of bile does not 
appear to be continuous, but that "short periods of rest are followed by a flow in a series of jerks, which appear to be caused by waves of peristaltic contraction, occasioned doubtless by the presence of fluid in the gall-bladder and large bile-ducts." As it appears to me that this is a misstatement of fact, originating in an erroneous inference having been drawn from the phenomena observed, and as at the present moment, when the pathology of liver diseases is receiving so much attention from the profession both at home and abroad, it is highly desirable that we should, as far as is possible, possess a correct idea of the mechanism of the biliary secretion, I venture to call attention to the following facts, more particularly as I think they not only give a ready explanation of why the flow of bile is apparently intermittent, but likewise that Mr. Copeman's statement originated in his having simply paid attention to the manner in which the excreted bile entered the receiving bottle in which it was collected after it had passed along a syphon tube, instead of observing how it flowed from the biliary ducts themselves. For in the case of a dog with an artificial biliary fistula, which Pıofessor Dastre of the Sorbonne has at present under observation in the Physiological laboratory, if one watches carefully the escape of the bile from the short cannula, it is seen that by slow degrees the cannula becomes fuller and fuller, until a sufficiency of bile has collected at its orifice for a drop or succession of drops to fall from it. A pause takes place during the reaccumulation of the bile, and then, after the bile has re-collected at the orifice of the cannula, the drop-flow is repeated as before. If, however, instead of allowing the bile to flow directly from the cannula, a piece of indiarubber tubing be attached to its orifice, and the bile be compelled to flow along it, as in Mr. Copeman's case, only the pause in the bile's excretion is observable, and the true cause of the intermission in its discharge from the duct remains undetected. Moreover, the mechanism of the intermittence of the excretion is easilyexplicable, when one remembers that from the fact of bile being a viscid liquid it takes some little time for it to collect in the cannula in sufficient quantity to admit of its dropping from its orifice. The pause in the excretion of the bile seems to be also in some measure due to the intermitting downward pressure of the diaphragm upon the liver and gall-bladder during the inspiratory effort. It may be as well for me to state that the log alluded to was operated on, on March 21st, 1889, by the common bile-duct not only being doubly ligatured, but the included part of it being completely cut away, so as to make perfectly sure that none of the bile could by the ordinary channel reach the intestines. And yet, notwithstanding this, the dog-although he had no bile given to him as in the case of Mr. Copeman's patient-has actually increased in weight. For, while before he was operated upon he weighed $16 \frac{2}{5} \mathrm{kilog}$, he now (on June 13th) weighs $16 \frac{1}{2}$ kilog. He has a splendid appetite, and is apparently in perfect health.

Laboratoire de Plyysiologie Expérimentale, Sorbonne, Paris.

\section{A a thitror}

\section{HOSPITAL PRACTICE, BRITISH AND FOREIGN.}

Nulla autem est alia pro certo noscendi via, nisi quamplurimas et mor. borum et dissectionum historias, tum aliorum tum proprias collectas habere, et inter se comparare.-MorgagnI De Sed. et Caus. Horb., lib. iv. Procemium.

\section{ST. THOMAS'S HOSPITAL.}

TRAUMATIC TETANUS TREATED BY NERVE EXCISION AND CHLORAL HYDRATE; RECOVERY; REMARKS.

(Under the care of Mr. MAKINS.)

WE agree with Mr. Makins in his opinion that the successful treatment of cases of traumatic tetanus should be recorded, for the disease is fatal in so many instances that the accumulation of evidence as to the efficacy of any method or methods of treatment is most desirabie. The local treatment may consist in the improvement of the condition of the wound if this be unhealthy, or, in addition, an attempt to destroy the conducting power of implicated nerves, by stretching, dividing, or resecting a portion of them, or by freeing them when involved in a cicatrix. In this case the nerve was inflamed, and excision of a portion of it was followed by marked improvement. Brown-Séquard" says: "Those who maintain that tetanus, when it has fairly begun, and attacked not only the head but the trunk and limbs, cannot be cured by these operations (amputation and neurotomy) have not read the details of the cases which have been published. ..... It is most important to give the chance to the patient." Nicaise is also in favour of it, even when generalisation of the disease has taken place. We have published during the last tive and a half years several cases in which this treatment appeared to be of value; also a paper by Dr. Macdougall ${ }^{2}$ on the subject, in which he mentioned two patients, for one of whom he divided the external popliteal and for the other a portion of the radial nerve, with success. He dwells on the importance of a careful examination of the wound for pain or tenderness in it or in the nerve leading to it, also on "Wood's symptom." During that period we have published accounts, more or less full, of fifteen cases of recovery from tetanus. In one ${ }^{3}$ amputation of the thumb was performed; in a second, ${ }^{4}$ excision of cicatrix and surrounding parts; in a third, a deep incision round the cicatrix ; in a fourth, ${ }^{5}$ division of the median nerve. We had placed many on record before that time. In $1887 \mathrm{Mr}$. Austin Meldon ${ }^{6}$ read a paper on Tetanus, and gave statistics of 937 cases collected by him, which possess considerable interest. He had administered hyoscyamus, belladonna, and conium in seventeen cases, with only four deaths, in his own practice. Of the others, in 370 treated by chloral, 83 recovered and 287 died; 135 treated by curare, 23 recovered and 102 died; 60 by nicotine, 3 recoveries, 57 deaths; 96 by opium, 4 recoveries, 92 deaths; 21 by conium, 3 recoveries, 18 deaths; 76 by cannabis indica, 12 recoveries, 64 deaths; 28 by bromides, 2 recoveries, 26 deaths; 103 by alcohol, 25 recoveries, 78 deaths; 41 by all other remedies, 17 recoveries, 24 deaths. He excluded from this table those in which the first symptoms were noticed later than the fifteenth day. In the fitteen cases to which we have referred, chloral hydrate was employed in four, and bromide of potassium in eight; hydrochlorate of morphia, strophanthus tabloids, and extract of physostigma in others; in seven, morphia was also used for the relief of pain. These are not, however, examples of the more acute form of tetanus, for the period between the infliction of the wound and appearance of symptoms varied from four days to four weeks. In the majority the use of chloral in repeated doses produced the most marked effect, conjoined with rest and the due administration of fluid nourishment. Verneuil in 1885 recommended strong doses of chloral and bromide, with quiet, \&c.; the opinion of the Royal Academy of Medicine in Ireland was in favour of a similar line of treatment ${ }^{7}$ in the previous year; whilst Dr. De Renzi ${ }^{8}$ and other Italians advised perfect rest with appropriate feeding, without the administration of drugs, and brought forward successful cases. There is no specific. In the acute variety of the disease but little has been done, whereas in the subacute and chronic forms there is much encouragement to perseverance in treatment. In one case which we recorded, ${ }^{9}$ as much as six ounces three drachms and a half of chloral were given during the attack; its action was carefully watched, and the dose increased or diminished ac. cording to the symptoms. We liave not space to consider other drugs which have been found useful. This case is one in which chloral was found of great value.

F. T- railway goods' guard, aged twenty-three, was admitted on Sept. 6th, 1888. He had been a temperate man, and had always enjoyed good health. He gave the following history. On Aug. 12th, while running, he trod on a piece of rusty iron hoop, a nail in which penetrated his boot and wounded the sole of the foot at the outer border of the ball of the great toe. The puncture closed in about a week; it was painful, but accompanied by no swelling or inflammation. On Aug. 23rd he noticed some stiffiness of the jaw, and on the $25 \mathrm{th}$, as he was sitting at tea, he was suddenly seized with stiffness in both legs, in consequence of which a

I Ashhurst's Encyclopadia of Surgery.

2 The Etiology of 'Tetanus and the occasional Value of Neurectomy. THE LANCE', vol. ii. 1884, p. 140.

4 Ihid., vol. i. 1887, p. 27.
5 Ibich., vol. ii. 1888, p 1013.

7 Ibid., vol ii. 1884, p. 236 , 9 rbid., vol. ii. 1884, p. 272 . 